\title{
FEM Analysis of Cold Flaring Process of SGP
} Pipe

\author{
Ryosuke Okushima, Shinichi Nishida, Junshi Ichikawa, Yuta Kashitani, Yujiro Nitta, \\ Atsuhiro Aoki, Yuto Takigawa, Hayato Aso, Hideto Harada, Akihiro Watanabe
}

Department of Mechanical Science and Technology, Gunma University, Japan

\begin{abstract}
This paper describes about finite element method analysis of cold flaring process of low carbon steel SGP pipe. These large diameter pipes such as ب216.3 $\mathrm{mm}$ are used for a plant as a flow channel of gas and liquid. The connection of pipes are generally welded at the plant. However, the other connecting method are required from a viewpoint of making the plant environment worse by welding. Therefore, flaring process of large diameter pipes were proposed. This flaring process is one of a method of pipe flange forming. The formed pipes were connected used with loose flange. Flaring process was generally hot process, thus it has some problem such as becoming complex of forming machine and accuracy of dimension. In this study, cold flaring process of SGP pipe was proposed to satisfy these requisitions. FEM analysis of cold flaring process were performed to clarify the optimum forming conditions for the flat length of connecting surface such as corner $R$. As a result, the optimum die corner $R$ was from $R 6$ to $R 9$.
\end{abstract}

Keywords-Cold Flaring Process, Pipe Forming, FEM Analysis, SGP Pipe.

\section{INTRODUCTION}

The large diameter pipes such as $\varphi 216.3 \mathrm{~mm}$ are used for a plant as a flow channel of gas and liquid. The connection of pipes are generally welded [1] at the plant. However, the other connecting method are required from a viewpoint of making the plant environment worse by welding. Therefore, flaring process [2] of large diameter pipes were proposed. This flaring process is one of a method of pipe flange forming. The formed pipes were connected used with loose flange. Flaring process was generally hot process, thus it has some problem such as becoming complex of forming machine and accuracy of dimension. In this study, cold flaring process of SGP pipe was proposed to satisfy these requisitions. FEM analysis of cold flaring process were performed to clarify the optimum forming conditions for the flat length of connecting surface such as corner R.

\section{FEM ANALYSIS MODEL}

Commercial finite element method analysis software DEFORM 3D Ver.10.2 was used for this study. Fig.1 shows the schematic illustrations of analysis model of cold flaring process. The proposed forming process has two steps. At first, the SGP pipe was formed by 45 degree punch. Next, after replacing the 45 degree punch, the 90 degree punch formed pipe flange. Formed flat position at flange is important factor. The formed pipe is jointed each other on the surface of this flat position with loose flange. Thus the flatness and squareness to longitudinal direction is required to prevent the leaking of air or gas. Therefore, the appropriate forming condition such as die $\mathrm{R}$ is needed to make a sound flange with larger flat area.

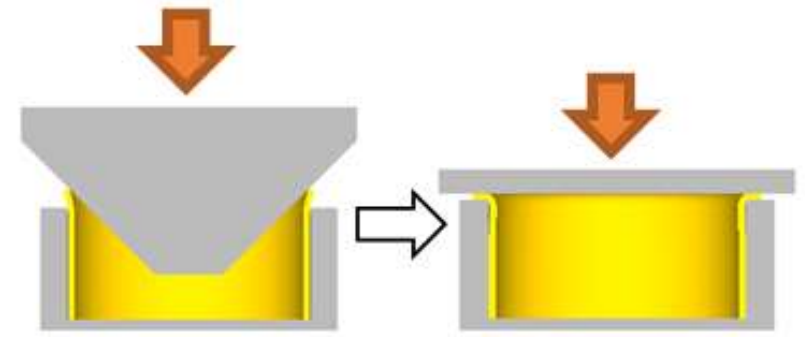

Fig.1: Schematic illustrations of analysis model of cold flaring process

\section{ANALYSIS CONDITIONS}

FEM analysis was operated to clarify the optimum die corner R in this paper. Fig.2 shows the example of die corner $\mathrm{R}$. Die corner $\mathrm{R}$ was changed as an analysis parameter. Designed die corner R were R0 mm, R3 mm, R6 mm, R9 mm and R12mm, respectively. The material of SGP is low carbon steel. Flow stress was obtained by tensile test. Tensile test piece was cut from SGP pipe. Fig. 3 shows the obtained flow stress curve. Table 1 shows the analysis conditions. Outer diameter of pipe was 216.3 $\mathrm{mm}$. Wall thickness was $5.8 \mathrm{~mm}$. The nominal diameter of this SGP pipe is 200A. The punch load was limited not to run over 200 tonns because the limit load of prototype machine is 200 tonns. 


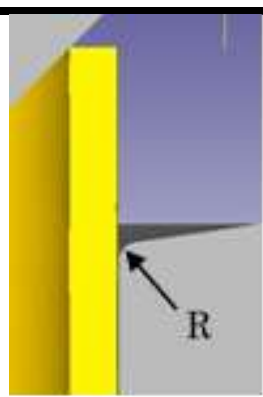

Fig.2: Example of die corner $R$

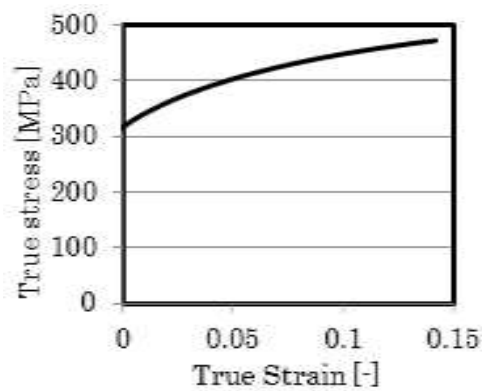

Fig.3: Flow stress of SGP pipe

Table.1: Analysis conditions

\begin{tabular}{|c|c|}
\hline Simulation software & DEFORM 3D ver10.2 \\
\hline Material & SGP \\
\hline Analysis model & Rigid plasticity analysis \\
\hline Outer diameter [mm] & 216.3 \\
\hline Wall thickness [mm] & 5.8 \\
\hline Number of elements & 115755 \\
\hline Friction coefficient & 0.12 \\
\hline Punch velocity [mm/sec] & 1 \\
\hline
\end{tabular}

\section{ANALYSIS RESULTS AND DISCUSSIONS}

Fig. 4 shows the analysis result of die corner R0 mm. The corner of die was dug into the SGP pipe. And the formed flange was not flat. It was supposed that the formed pipe was damaged. In addition, it was supposed that the die corner was damaged by local concentration of stress. Thus, die corner R0 mm was not recommended.

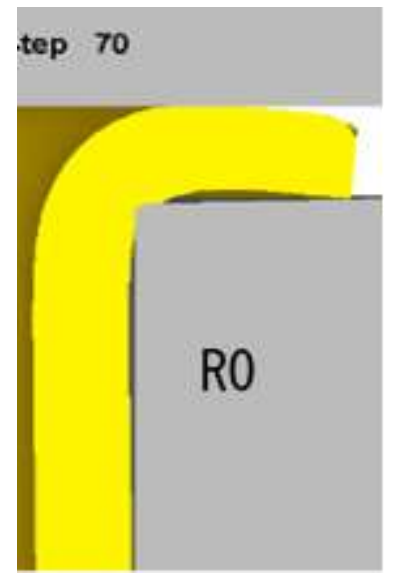

Fig.4: Analysis result of die corner $R 0 \mathrm{~mm}$
Fig. 5 shows the analysis results of die corner R3 mm, R6 $\mathrm{mm}$, R9 $\mathrm{mm}$ and $\mathrm{R} 12 \mathrm{~mm}$, respectively. Constriction of pipe end was occurred. The larger die corner $\mathrm{R}$ became, the smaller the gap between die and SGP pipe became. Flat area at joining position of die corner R12 mm was smaller than that one of die corner R $3 \mathrm{~mm}$. It is supposed that longer flange length before flaring is needed to obtain larger flat area in R12 mm flaring process. However, it is needed to consider the formability of SGP pipe because pipe expansion ratio is increasing. Therefore, it is supposed that the optimum die corner $\mathrm{R}$ is from $\mathrm{R} 6 \mathrm{~mm}$ to $\mathrm{R} 9 \mathrm{~mm}$ with considering the flat area and the gap between the die and SGP pipe.

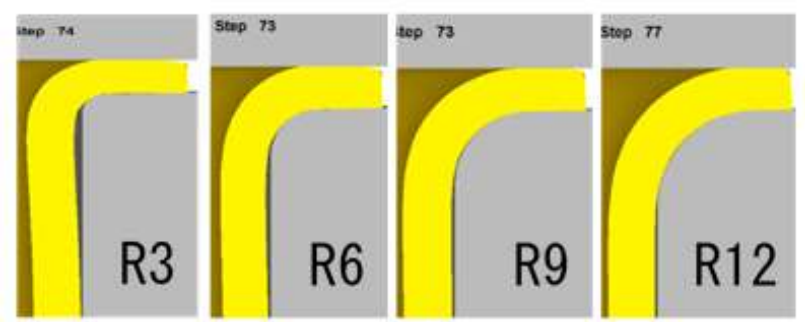

Fig.5: Analysis results of die corner $R 3 \mathrm{~mm}, R 6 \mathrm{~mm}$, R9mm and $R 12 \mathrm{~mm}$

\section{CONCLUSIONS}

1. Finite element method analysis was operated to obtain the optimum die corner $\mathrm{R}$ of cold flaring process.

2. Die corner $\mathrm{R} 0 \mathrm{~mm}$ was not recommended because of digging into SGP pipe.

3. The larger die corner $\mathrm{R}$ became, the smaller the gap between die and SGP pipe became.

4. Optimum die corner $\mathrm{R}$ was from $\mathrm{R} 6 \mathrm{~mm}$ to $\mathrm{R} 9 \mathrm{~mm}$.

\section{REFERENCES}

[1] Baskoro Ario Sunar, Masuda Rui, Kabutomori Masashi and Suga Yasuo, Welding Penetration Control for Aluminum Pipe Welding Using Omnidirectional Vision-based Monitoring of Molten Pool, Quarterly Journal of the JWS, 27(2), 2009, 1721.

[2] X.L. Hua and Z.R. Wangb, Numerical simulation and experimental study on the multi-step upsetting of a thick and wide flange on the end of a pipe, Journal of Materials Processing Technology, 151(1-3), 2004, 321-327. 